\title{
Merging Geo-Solar Exergy Storage Technology (GEST) and Environmental Quality Management (EQM): A Practical Solution for NZEB Retrofit
}

\author{
Lowell Lingo ${ }^{1}$, Kristin Lingo ${ }^{1}$, and Mark Bomberg ${ }^{1,2}$ \\ ${ }^{1}$ DFI Enterprises, Inc., Morrisville, NY, USA \\ ${ }^{2}$ Clarkson U., MAE, Potsdam, NY, USA
}

\begin{abstract}
A decade ago, Geo-solar Exergy Storage Technology (GEST) was introduced as a means of utilizing natural, diurnal and seasonal transfers of exergy between a building and its surroundings to significantly decrease heating and cooling requirements. This is accomplished by retrofitting the structure with a dynamic skin to the existing building enclosure that is provided with internal conduits to carry air and fluids, for coupling geothermal storage surrounding the building with the exterior environment. This system was developed by engineers as an affordable, low-tech solution for providing seasonal heat storage in cold climate regions. Meanwhile another holistic but high-tech means to the same goal was initiated by an international group of building scientists by defining concepts for environmental quality management (EQM). Using heat pumps, 'smart controls', and newly developed wall coating materials, a fully integrated HVAC (plus moisture control and indoor air quality (IAQ)) system was proposed. The experience gained with GEST methods is now combined with the leading edge of Building Science to permit our international team to reevaluate the concept of Geo-solar Exergy Storage and Dynamic Building Enclosure incorporated in a system with a heat pump as a new basis for retrofitting buildings in any climate.
\end{abstract}

\section{Introduction}

For more than four decades, since the first energy crisis, engineers in the United States have been searching for a better solution for retrofitting existing buildings. Many types of energy saving measures have been tried, including passive houses and NZEB (Net Zero Energy Building). All the specific technologies resulted in far more comfortable living, yet the progress in new construction has not introduced a dramatic change in national scale and we are still talking about $40 \%$ of our energy being used for buildings; Why? New construction or very expensive modifications are required for the passivhaus or NZEB. The vast majority of the population living in detached dwellings can't afford new construction, thus technology must include a means to retrofit existing homes to NEZB. Older homes have been improved with added insulation, improved windows and doors, etc., but diminishing returns have reduced progress on further energy conservation improvements. A major shift in our approach toward the usage of renewable energy sources, our approach to the building envelope function (or both) seems overdue. Ironically, in cloudy Syracuse NY (Lat. $43^{\circ} \mathrm{N}$ ) from the $1^{\text {st }}$ of January through the first week in April, while we are bringing in loads of energy to keep our homes warm, the sun delivers as much energy to our rooftops as we will consume for the entire year [1] as shown in Figure 1. Historically the building envelope has functioned as a barrier to energy transfer between the outside and the inside; we propose it rather act as a filter.

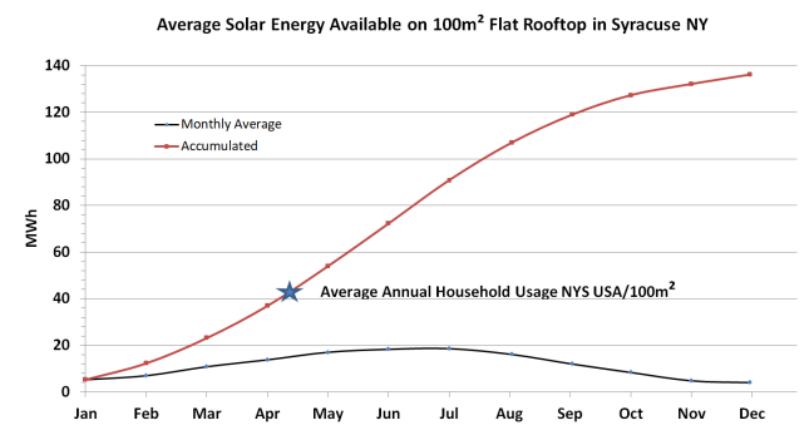

Fig. 1. Solar energy available on the footprint of an average house in central New York, USA.

A dynamic building envelope with an equivalent variable resistance, coupled to the heat storage capacity of the ground (or large volume of water) shunting extreme temperatures to and from storage while allowing moderate temperatures to pass, is the principle behind GEST. Integrating the constant energy source from the sun into the building and its surroundings we believe might be the technological breakthrough that will allow retrofit construction to nearly match new in energy conservation.

Science tells us that new buildings must be designed in a holistic manner [2] and the introduction of IDP (integrated design process [3]) brought the correct platform to do it. The authors suggest that this holistic process be applied to retrofit construction. In this paper we propose such an approach, which should be:

- Applicable to new and existing buildings

- Affordable to homeowners with lower income

- Economically and ecologically sustainable

\footnotetext{
* Corresponding author: lelingo@syr.edu
} 
- $\quad$ Applicable for all climates, thereby simultaneously addressing both heating and cooling.

Ten years ago, we introduced the concept of affordable retrofitting with a dynamic building envelope, as mentioned previously as Geosolar Exergy Storage Technology (GEST) [1]. Although theoretically sound and economical, each installation requires design work based on the architecture of the dwelling and its location. Furthermore, a sizable amount of ground is needed for energy storage and automatic control has not been fully addressed. It does however present a far greater potential for reducing purchased energy requirements because it makes use of the renewable energy source described above.

Today we merge this concept with another technology, namely EQM (environmental quality management). EQM encompasses considerations related to occupant-centered indoor climate (OCC) $[4,5,6]$. EQM includes water-based heat pumps, integration of sub-systems with automatic steering and control systems and dynamic operation of indoor environment. It also proposes a two-stage construction process that provides universal cost-benefit analysis to new construction and retrofitting of existing buildings. We expect the result will be that soon the retrofit of many older homes to NZEB will not only become economically feasible, but will be commonplace.

\section{Geo-solar Exergy Storage Technology}

\subsection{A note on Exergy}

Exergy is the energy in a system that is available to be used. Unlike energy, which can "neither be created nor destroyed", when a system reaches equilibrium the exergy in the system has been lost and is equal to zero.

As used in GEST, exergy generally refers to temperature differentials within the system, which includes the building(s), the ground surrounding them, the surrounding atmosphere, the sun, and where radiational cooling is desired, the night sky. As seen from figure 1, the system is not closed. Exergy between system components changes with the sun path, cloud cover, weather systems and seasons. Part of the system goal is to use the storage capacity of the ground (or a storage tank) to 'clip' the hot and cold diurnal and seasonal peaks to allow downsizing the HVAC system. A heat pump (HP) is an exergy creating device. The HP takes a fluid at some given temperature and transfers heat from it into another fluid creating two fluids with a temperature differential, i.e. adding exergy. It requires some energy from an outside source. Then HPs incorporated into GEST could allow precise management of exergy substantially increasing its effectiveness.

\subsection{GEST background}

Figure 1 demonstrates the obvious fact that the least amount of useful energy we receive is during the time we need it the most, so making the best use of the energy available in our back yard will depend on the ability to store some of it in the ground around the building. Thus the GEST system originated from the review of earth-coupled shelters in a quest to employ ground heat storage so that the foundation, the basement (and thus the ground floor) would not be cold. Out of many different designs reviewed, features from three creative methods melded into what would become GEST. Passive Annual Heat Storage (PAHS) was described by Hait [7]. This earth shelter is essentially a home partially buried under an earthen "insulation umbrella" that traps solar heat gained in the summer and stores it to keep the inside walls warm through the winter. Annual Geo Solar (AGS), described by Stephens [8] employs duct work to circulate hot air from beneath the metal roof down through the ground at a depth beneath the concrete floor slab such that the time it takes heat to migrate up to the slab corresponds to the time elapsed between the cooling and heating seasons. To contain heat beneath the ground, the insulation umbrella concept was also employed. This system makes use of the roof as a thermal solar collector and results in a more direct and efficient scheme to gather and deliver heat to the earth. With the roof aircooled, the cooling load is also reduced.

The third and most useful design was the double façade or buffered house as presented by Booth [9]. Buffering is an approach whereby a temperate zone is incorporated between the interior and exterior spaces, such as a closed-in-porch. A buffered house may also be one with a double façade having an interstitial air space. Booth's house was a house within a house, with the air between the two houses circulating through the basement. With this system, if indoor temperature of the house $\left(\mathrm{T}_{\text {in }}\right)$ is $20^{\circ} \mathrm{C}$, and the outdoor temperature $\left(\mathrm{T}_{\text {out }}\right)$ is $-10^{\circ} \mathrm{C}$, the $\Delta \mathrm{T}$ across the entire wall is $30^{\circ} \mathrm{C}$. The temperature between the walls $\left(\mathrm{T}_{\mathrm{w}}\right)$ however, circulating through the basement is at some temperature in between, say $6^{\circ} \mathrm{C}$ and this is the temperature the heating system 'sees' as the outdoor temperature. The rest of the temperature difference is made up by the cooling of the basement, which slowly recovers temperature from the ground source. The process functions in reverse during the summer. Where $\mathrm{T}_{\mathrm{w}}<\mathrm{T}_{\text {out }}$, the interior walls are cooled, and the basement sinks heat, eliminating the need for AC, and storing heat in the basement walls and floor to be recovered the following winter. This is an interesting concept, but expensive, as two framed envelopes are required, and definitely not suitable for retrofitting to most existing houses. The biggest problem with it was made evident when modeling the buffered house to the climate in Syracuse, NY. The result was that the buffered wall and the same insulation without the interstitial space performed almost equally well. Tossing out all the data we did not like, however gave us the dramatic results we were looking for. Examination of what was tossed revealed that although the system performed extremely well in both cold and hot periods, during periods in between, as $\mathrm{T}_{\text {out }}$ approached $\mathrm{T}_{\mathrm{w}}$ the $\Delta \mathrm{T}$ across the exterior wall reached zero and the exterior wall insulation became ineffective. Further, as $T_{\text {out }}$ exceeds $T_{w}$ the heat plant is working 
harder than it would without the exterior wall. So, the question of how to throw out only the undesired data in the real world was posed. The answer was to enable the duct system to the interstitial space to be opened or closed as conditions changed. Thus, the ground-coupled dynamic (GCD) wall was born.

\subsection{GCD wall utilizes geo-solar exergy storage}

The theory was now sound; not yet economical. But the high potential of the buffered wall warranted an examination of how to make it into an entire system that is cost-effective, while ensuring the following criteria are met:

- The envelope performs dynamically under varying weather conditions, with coupling on or off.

- A retrofit can be easily accomplished.

- The thickness of walls is limited.

This effort resulted in an exterior panel as depicted in figure 2. The dual-wall configuration is replaced with a 'skin' over the existing exterior sheathing after removing the original siding. An air cavity is created against the old wall by placing a series of 19x50 mm thick wood strips spaced $400 \mathrm{~mm}$ apart to form a serpentine air duct as shown. This is covered with 25 $\mathrm{mm}$ thick, foil-faced polyisocyanurate boards. Each end of each air path is connected to the basement via a duct system constructed from a $100 \mathrm{~mm}$ drain pipe, with inline duct fans and shutter valves for closing the line as conditions warrant. The horizontal furring strips creating the air path, over the vertical studs inside the wall, interrupt thermal bridging in the framed wall. At the same time, the outer surface seams are caulked and taped and an air barrier material is installed.

Figure 3 is a cross-section of this wall depicting the temperature profiles from the two panel sections taken at two different times on a January day; at 04:00 and again at 15:30 the same afternoon. Outside air at those times was $-16^{\circ} \mathrm{C}$ and $-12^{\circ} \mathrm{C}$ respectively. Seven temperature probes placed through the wall, as shown, allow the observation of the heat profile under various conditions. The two panels are similar, except that one was running in dynamic mode, with basement air circulating through the air gap, then returning to the basement (A1, A2), whereas the other was in static mode with the air ductwork closed off (B1, B2).

Table 1 shows the temperature drop across the interior wall to the air gap in both modes of operation. Note that for both GCD (A1, A2) traces, the temperature drop across the interior wall to the airgap $\Delta \mathrm{T}$ is much smaller than on the static side (B1, B2), and much less dependent on the outdoor temperature. The static wall transfers almost twice the energy of the GCD wall at a $\Delta \mathrm{T}$ of $16.5 \mathrm{C}$ and 2.8 times more at a $\Delta \mathrm{T}$ of $23.8 \mathrm{C}$. The additional benefit of the retrofit is also evident from results given in the last two rows of Table 1, in which results are shown without the added skin. Under these conditions an improvement of a factor of two is made simply by adding the skin without the earth connection.

Equally impressive effects were measured in cooling, especially when the summer sun was shining directly upon the wall. The dynamic performance can be improved by drawing air through an air-earth heat exchanger during summer months [10], and in a cool climate where the shallow ground temperature is below $16^{\circ} \mathrm{C}$, the need for air cooling could be eliminated.

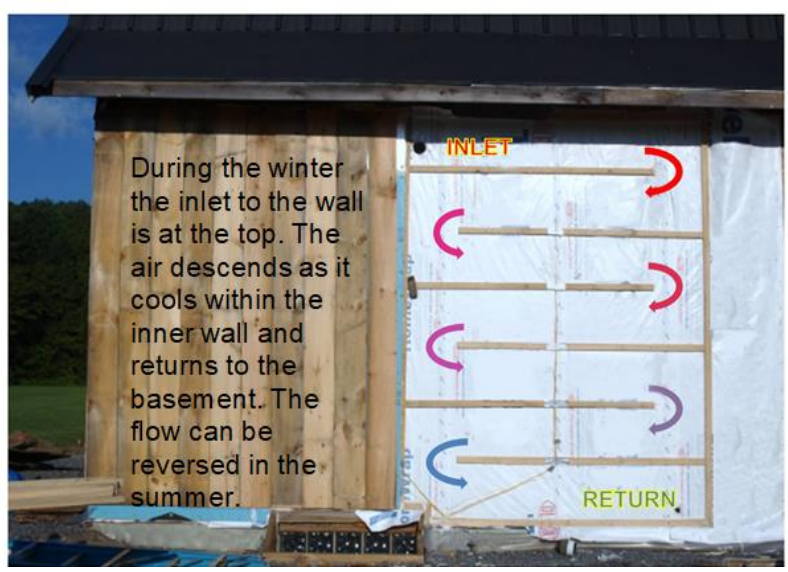

Fig. 2. This inexpensive retrofit over the sheathing of a wood framed house forms the basis of the GCD wall that will significantly reduce both heating and cooling expenses.

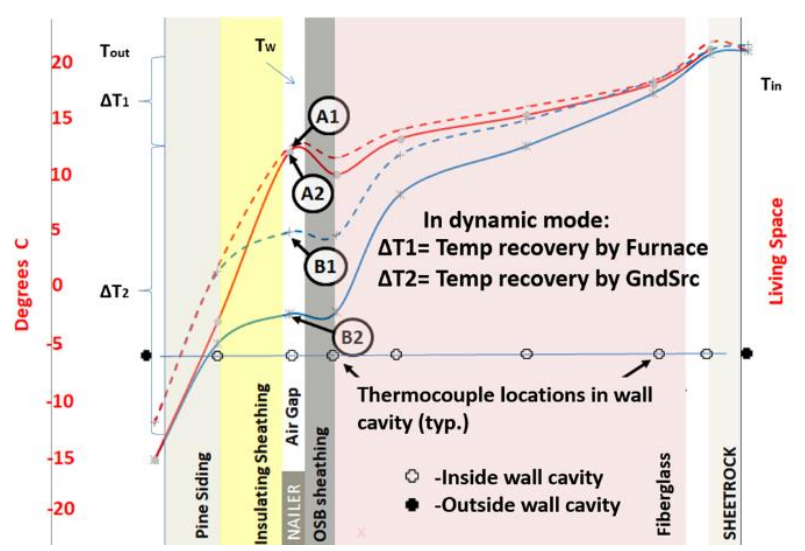

Fig. 3. Temperature profiles through the GCD wall on a cold day running both in static and dynamic modes.

Table 1: Comparison of static and dynamic wall operation (inside temperature is $21.3^{\circ} \mathrm{C}$ )

\begin{tabular}{|l|l|l|l|l|l|l|}
\hline Trace & Time & Tout & Tw & $\Delta \mathrm{T}$ & Ratio & $\mathrm{W} / \mathrm{m}^{2}$ \\
\hline A2 & 0400 & -15.6 & 12 & 9.3 & 1 & 3.1 \\
\hline A1 & 1530 & -12.2 & 12.4 & 8.9 & 1 & 3.1 \\
\hline B2 & 0400 & -15.6 & -2.5 & 23.8 & 2.8 & 5.9 \\
\hline B1 & 1530 & -12.2 & 4.8 & 16.5 & 1.9 & 8.5 \\
\hline- & 0400 & -15.6 & - & 36.9 & 4.0 & 12.0 \\
\hline- & 1530 & -12.2 & - & 33.5 & 3.76 & 13.2 \\
\hline
\end{tabular}

\subsection{The GCD roof and ground storage: an additional source of renewable energy.}

Having established a practical method of utilizing heat stored in the ground, the next step was to see how we might use the excess energy falling to on the roof to cool the building, or to add to our naturally stored geothermal storage bank for winter use. It turned out that both could be accomplished quite economically with a Ground Coupled Dynamic roof. Don Stephens' Annualized Geo-Solar house pumped hot air from beneath the roof into the ground beneath the house, 
cooling the roof and warming the ground; trapping the heat with John Hait's insulation umbrella around the perimeter of the building. Once again, with retrofitability and economy in mind a design for implementation (DFI) was performed.

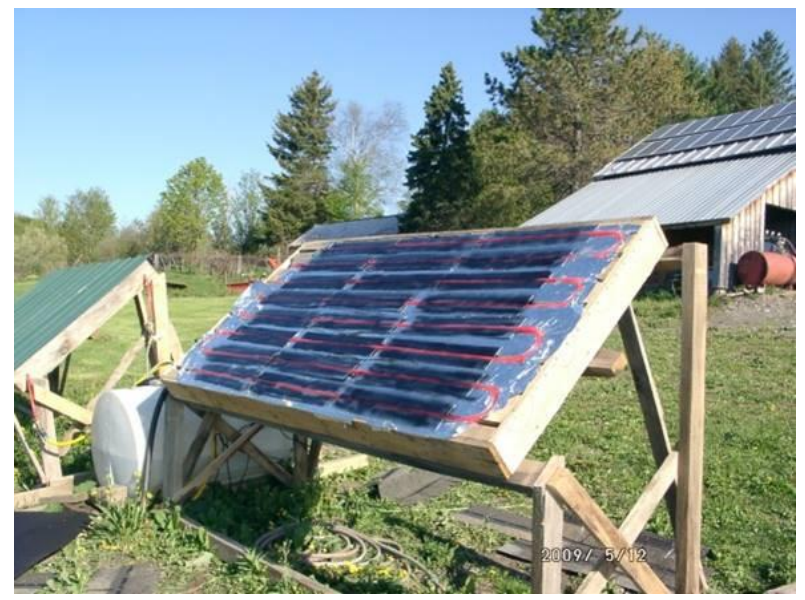

Fig. 4. Solar roof panel prototype with PEX, RHT, and Al HTP prior to asphalt shingle application. A second panel with steel roofing cover sits to the left.

Twin solar panels, each $3 \mathrm{~m}^{2}$ were constructed; one under steel roofing material and the other under asphalt shingles. Due to the expense of copper, we avoided its use and utilized PEX radiant heat tubing (RHT) with added aluminum heat transfer plates (HTP) to aid in heat transfer to the back of the tubes. Figure 4 shows the RHT layout under what will be the asphalt roof test panel, with the steel roof panel operating in the background. Black steel was eventually built into the prototype GEST house.

Different configurations were tested; output rates $120-150 \mathrm{~W} / \mathrm{m}^{2}$ were typical with the tubing alone, but doubled with the addition of the HTPs, exceeding the efficiency of PV panels. In one configuration with a tube density about $40 \%$ greater than what is shown in the figure, a peak of over $70 \mathrm{~W} / \mathrm{m}^{2}$ was achieved. The system intercepts heat prior to its entering the building (greatly reducing or eliminating the need for $\mathrm{AC}$ ). The heat is rapidly transferred via a water to water heat exchanger into a 4500 liter cistern. The cistern is connected to ground loops in the earth around the perimeter of the building. The slower cistern to ground transfer of heat to the ground then can occur over a 24 hour period. The building stays cool through the roof cooling, and the earth surrounding the building is storing heat so that as the heating season approaches, the basement becomes warmer. This warmth, transferring into the basement through the walls is will provide the heat source for the airgap in the GCD wall in the winter. It also creates the potential to have a heat pump work more efficiently than it would with a colder ground loop. Heat is transferred into the ground from the cistern via RHT laid out along the basement wall in three layers about $1 / 2$ meter above one another at $1 / 2$ meter horizontal intervals to a distance of about 5 meters from the building wall as shown in figure 5 . About $1 / 2$ meter above the top layer, a roughly $100 \mathrm{~mm}$ layer of expanded polystyrene insulates the soil. This is covered by heavy

Fig. 5. Geothermal loop from which the data in figure 6 was

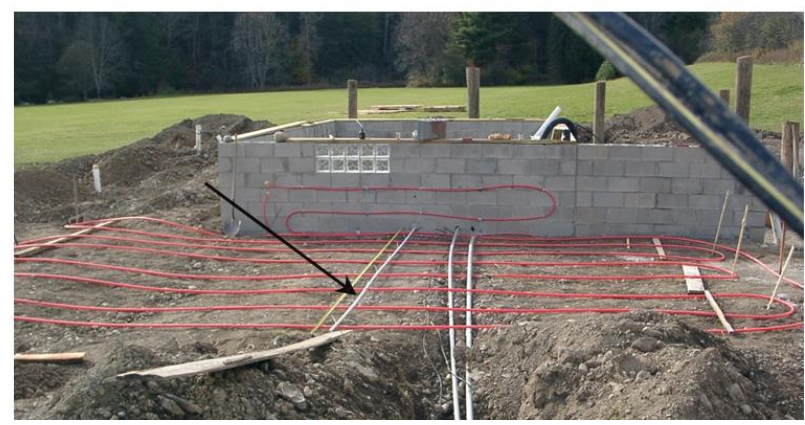

taken. The arrow indicates thermocouple array conduit with 12 TCs across the width. Two identical loop-TC sections are positioned $1 / 2 \mathrm{~m}$ above and below this loop.

polyethylene sheet to keep the soil dry, and another $100 \mathrm{~mm}$ of $\# 1$ crushed limestone and $20 \mathrm{~mm}$ of topsoil to support lawn growth. Beneath the basement there is also a pair of "slinky" coils of PE pipe. These deeper coils can be used to sink or source ground temperature heat but not for heat storage because excess heat would be lost in the groundwater. In cases where a sufficient volume of ground is accessible around a building, a considerable amount of heat can be stored in the ground. Figure 6 shows the results of spring ground warming in one of the cells in the GEST prototype. Operation of the system was manual, requiring startup of the pump in the morning and switching valves between the four separate roof panels as the sun completed its daily path, then shutting the system down at sunset. The system was not operated on overcast days, and was shut down from May 7 - May14. With automated operation the temperature increase could have been significantly higher.

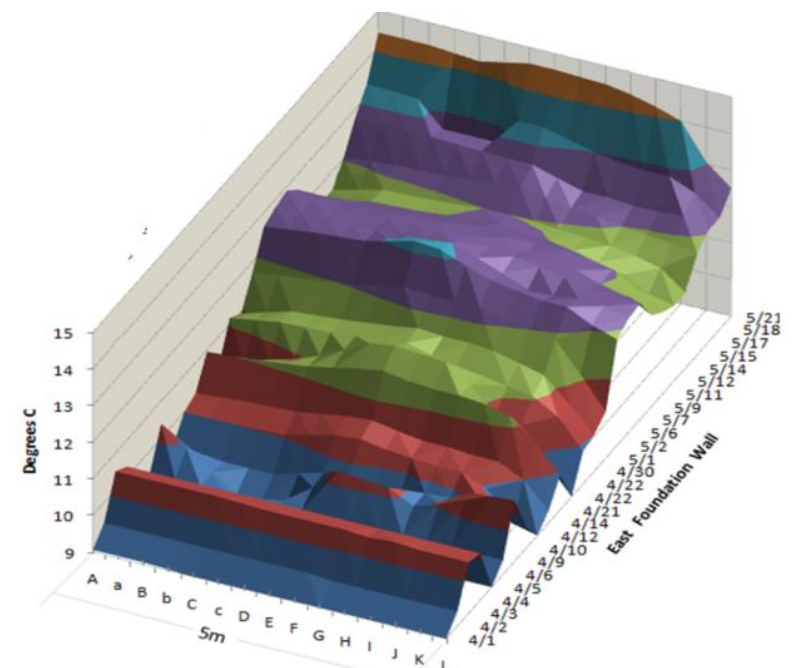

Fig. 6. Spring ground warming from solar roof without automatic operation. Note valley where system was shut down from $5 / 7$ through $5 / 14$ 
This emphasizes the need for the early development of a control system, as published in an analysis of EQM technology [4]. Several other observations from the previous validation of the GEST test building corroborate this. For example, a control system is needed for counteracting temperature changes that occur rapidly and unpredictably in different parts of the building. When the sun or wind act on one side of the building, the opposite side is shaded. The GEST system at present requires valve operation, switching blowers or circulation pumps, and monitoring temperatures of heat storage cells to be able to control the flow of heat in either direction. Some of the automation could be simple, consisting of differential thermostats, and automatic valves. Some requires more sophisticated control to maximize the efficiency of the low-grade energy storage and recovery management system. But automation is the key in getting this promising system to the forefront of large-scale implementation.

\section{Ground coupled dynamic concepts create a basis for retrofit technology implementation}

The exergy swings that form the basis for this technology have two major components, diurnal and seasonal. The large amount of ground heat storage is important for saving summer heat for a six-month winter period, whereas the advantages of dynamic operation of buildings are easier to observe with day to night or week to week changes. Buried cisterns or insulated water buffer tanks for the heat pump can mimic the effect of ground storage because the heat capacity of water is higher than that of the earth, and water temperature can be better controlled than the natural flow of heat through the ground allows. Furthermore, placing a tank next to the basement and insulating a small perimeter around the house provides some of the same advantages as the insulation blanket.

Dynamic operation of heating, cooling and ventilation systems is controlled by a system but there is a major problem caused by the lack of field performance models. As we discussed elsewhere [11,12], currently used energy models are parametric and the EQM technology requires real-time control under variable climatic conditions. The EQM control system collects information from all subsystems and uses advanced control algorithms to set parameters for heating, cooling, and ventilation based on indoor and outdoor climatic conditions. As heating/cooling pipes are located in the walls, water flow and temperature sensors must also be placed there. Some rudimentary control algorithms may be delivered with the equipment but fine tuning (optimization of the heating/cooling or ventilation devices) will be done during the operation of the system. For this purpose, a building automation specialist must be incorporated in the design team.

In the original work a prototype for geo-solar exergy storage was built and validated for individual concepts of energy capture, storage, and recovery in both heating and cooling modes. Now we are reviewing this design process to see if a retrofitting product can be made as needed to enter the marketplace. In this configuration, we propose the following components:

1) An "energy package", including a heat pump with one or two buffer tanks, air handling equipment and if available and practical one or more ground storage cells

2) A dynamic building enclosure retrofit, consisting of a panelized 'skin' containing thermal insulation and conduits for ventilation and hydronic heating

3) An automated control system tying the components together

4) Instructions and training for installation and integration of the above two items in a number of combinations as needed for the selected design

This product will eliminate much of the construction detail such that the design becomes a selection and layout of modularized components. It will facilitate different design options such as connecting one or both buffer tanks to an exterior horizontal ground exchanger and /or solar panel and heat pump or introducing moisture control to the dynamic ventilation channels in the exterior wall.

In effect, we are striving to obtain an integrated solution to heating, cooling, ventilation, indoor air quality, and moisture control that operates with prescribed types of control to obtain a high air quality retrofit to any existing dwelling in any climate.

Bomberg [2] states that as of 1945, most buildings eliminated the effect of thermal mass on energy consumption by introducing a large area of windows with leaky wall-window interfaces. To counteract the air infiltration and solar energy transferred across the wall, the stability of indoor air temperature was improved and eliminated any dynamic performance. As the large area of glazing delivers solar radiation to the floor, water systems, being more effective in heat air recirculation, replaced forced air heating. Today, North American housing uses $1 / 2$ to $1 / 4$ of the energy used 40 years ago. With an efficient building enclosure even the hydronic floor system can ensure thermal comfort without cooling.

So, the natural progression is to use a heat pump (HP) with two buffer tanks. The hot tank is integrated with solar thermal panels that typically are placed as an outer skin in the wall facade or as a shading device above the solar-exposed windows. A cold tank is used for summer cooling. In a warm climate this is reversed - walls and roof are cooled and the hot tank is integrated with the domestic hot water tank.

\section{Discussion}

Until now, building science has failed to provide the basis for a uniform technology for the reduction of energy consumption in existing buildings and thereby reducing $\mathrm{CO}_{2}$ emissions. Yet, recent international developments, including an ambitious NY State energy plan, bring us to the conclusion that now is the time to change thinking about and the approach towards achieving sustainable built environments. 


\subsection{A new thinking paradigm}

The new thinking paradigm is an integrated system, operated in a dynamic fashion, and designed on the basis of interaction of building science, the local environment, and automatic control systems. In this endeavor we will develop an open-ended design process that can be used as a basis for retrofitting all buildings.

For passive houses, these critical factors are not addressed: (a) interaction with an external climate $[1,14]$, (b) quality of indoor environment in multi-unit residence, (c) dynamic operation of buildings to increase contribution of hygric and thermal storage $[1,15,16]$ and, (d) variance in economic conditions $[17,18]$. Therefore, a universal system is introduced in this paper that expands the passive house approach and is adaptable for different climates and economic conditions. The proposed system:

- Taps an underutilized renewable energy source with Geosolar exergy management, by integrating heating, cooling and ventilation with interior and/or exterior enclosure of the building and short and/or long energy storage in tanks or earth near the building

- Integrates solar-thermal panels with building envelope, including the roof, the exterior walls, and/or windows

- Adds ventilated insulation layers, and moisture buffer/multifunctional materials to improve performance of the existing building assembly

- Introduces a new moisture management of walls allowing an over-pressure of ventilation air

Taking an example of NY State where $31.2 \%$ of housing units were built before 1939, and for which $33 \%$ used fossil fuels for heating, one can assume that in the span of the next 10 years at least $25 \%$ of the old housing stock will use the passive house $(35 \%$ reduction) and the other $25 \%$ the proposed retrofitting technology (55\% reduction). We estimate a total 52,500 $\mathrm{MWh} / \mathrm{yr}$. in reductions and thus we obtain a substantial contribution to NYS energy goals. There is, however, a substantial challenge caused by a predicted $\$ 17$ billion market estimated for 'Smart Homes' in the USA in 2023. The development of automation for system control of an integrated building retrofitting system must be in parallel and thus independent of the entertainment market but must nonetheless use similar communication protocols. One needs to deal with dynamically operated buildings where the system for environmental quality management includes a prepackaged heat pump, system of interior panels for hygrothermal upgrade and heat distribution and an advanced system for indoor environment controls. The objective of the project being an affordable retrofit implies several decisions on the selection of simple equipment and a multi layered control system.

\subsection{A path to affordability}

The actual definition of affordability does not imply that an object has a low price, but rather that its benefits exceed its cost. This is somewhat similar to the concept of defining quality as being equal to or exceeding the expectations of the client. We only present a short summary here; a more detailed background can be found in reference [14].

Today an investor making a cost-benefit analysis typically expects a 10 to 15 -year return on investment (ROI). The ambitious goal of obtaining a zero-energy building however is a 'major overhaul' and will likely require a considerably larger expenditure than would be expected for most other home improvement projects. The return however should last for the lifetime of the owner and of the building. Thus, to make the NZEB goal affordable for a maximum number of homeowners, we advocate a multi-stage design, construction, and application process.

The new fully integrated and automated retrofit requires a far greater complexity in design with the addition of the HPs, automated control systems, ventilation and moisture handling; combined with the fact that these systems are all to be integrated into the building's unique environment. But the neatly integrated systems have components that work well independently regardless of system completion as we demonstrated in Figure 2 and in Table 1. The uniqueness of each retrofit situation will require a unique design. The first step should be a screening of the existing situation. This might be a 'free' marketing service or might be locally subsidized. The preliminary screening will include a review of the building's current operating efficiency and the owner's ability to pay for changes. Then a plan fit for the situation is proposed. For example, two similar houses in the same neighborhood are screened. It is determined that house $\# 1$ has a relatively new natural gas heating system, but the insulation in the walls has deteriorated and is very poor. House $\# 2$, on the other hand, has good wall insulation, but is heated by an old oil furnace in need of tuning. Although the ultimate route to a NZEB might be the same for the similar houses, the economics of the situation suggest that the GCD walls be installed on house \#1, and that a packaged air source heat pump with individual room delivery units be installed in house \# 2 . In both cases, minimal expense will get a good return on investment and they get extra years out of the still wellfunctioning parts of the systems. At the same time almost all of their investment goes directly toward the ultimate goal. Some number of years later, when it is affordable, house \#1 gets a HP to connect to the wall panels and house \#2 replaces the air delivery units with the GCS panels and both are NZEBs. Another example in cost reduction is with the solar roof. If a roof needs replacement it is a small additional expense to make it into a solar roof. As this type of NZEB retrofit becomes mainstream, roofers will give customers the option of installing coils beneath a new roof in preparation for future retrofit. And even prior to the complete retrofit, the coils can be used to heat or preheat DHW, heat a pool, supply heat to a heat pump, or even for melting snow on the roof. Exterior wall siding replacement to exterior GCD paneling has similar cost saving implications. 
For the two-stage solution to be successful one must design both stages at the same time; only the construction process is divided into two parts to secure funding when the basic level of the building is in existence. The second stage of the project will be financed either by a builder or the house-owner applying for a long-term construction loan.

Currently in the U.S., a number of financial institutions will provide a loan based on existing capital resources and the federal government is in the process of revising the appraisal documents for buildings. All that a homeowner needs is a detailed cost of stage two for investment in reducing energy expenses. As lenders calculate a borrower's expenses as Principal, Interest, Taxes, and Insurance (PITI), adding energy bills to their calculation (PITI+E) opens an interesting, new investment opportunity. Observe that this investment does not increase the cost of living, the local economy gets a boost, and yet, $\mathrm{CO} 2$ emissions are dramatically reduced. A win-win-win situation.

As the two-stage solution is also suitable for retrofitting of existing buildings, we include the Montreal project [19] as an example. Atelier Rosemont (2016) in Montreal, Canada is a cluster of buildings designed to be retrofit over a period spanning 10 years. The energy reduction calculated as zero in 2008 when the building was erected, were completed over the ten years as follows:

- High performance enclosure; common water loop; solar wall $-36 \%$ reduction

- Gray water power - the cumulative energy reduction grows to $42 \%$

- Heat pump heating - all passive measures give $60 \%$ reduction

- Domestic hot water with evacuated solar panels a further $14 \%$ reduction

- Photovoltaic panels reduce the total energy to the total energy reduction of $92 \%$

\section{Concluding remarks}

The development of GEST redefines the function of the building envelope. A static insulator, isolating the indoor environment from the elements becomes an active filter, moderating the indoor temperature by controlling the migration of desired heat bidirectionally through the interior wall, while shunting excess heat between the atmosphere and the capacitance provided by ground storage. In doing so, it makes use of relatively small differences in naturally occurring atmospheric temperature levels. Leveraging these changes can provide us with another significantly large renewable energy source from ground storage and create an economic incentive for retrofitting a dwelling [20]. One might think this would be a real gamechanger in energy conservation, but such has not been the case because it is far from a turn-key system:

- As currently presented, there is no built in automation in the system. When the sun shines, on a given side of the house, a decision has to be made as to where the associated heat should be directed. If not through the roof, a circulating pump has to be started, and an appropriate series of valves have to be set directing flow. The reverse is necessary as the sun move off the section.

- Input and output temperatures of all the fluid flow lines for the solar collectors, the storage reservoirs, all the heating and cooling zones, as well as for the GCD wall zones must be monitored in order to be able to make all these valve and pump setting decisions.

- The solar roof is quite straight-forward, but GCD wall panel sections and ground storage potential vary greatly at each location, so custom design work is required before a retrofit can take place.

- Any changes to standard design practices may be held up in certain locations due to red tape with building codes.

Without these issues being addressed, GEST would likely remain no more than an interesting theory; but enter EQM.

EQM is an environmental quality management system based, among other things, on heat pumps and advanced system controls. A heat pump is almost by definition an exergy manager; it takes fluid at one temperature (equilibrium) and separates it into fluids at varying temperature, i.e. adds exergy. GEST under natural conditions is limited by system equilibrium, but the addition of heat pumps and controls would allow, for example the 'tweaking' of air temperature in the GCD wall for maximum efficiency, or the temperature of water in the solar collector to be raised slightly to continue heat transfer into a warming cistern, taking advantage of late afternoon sun. Symbiotically, GEST also improves EQM by introducing an additional energy and dynamic building envelope to the system, allowing heat pumps to run more efficiently and perhaps to even be downsized.

With EQM, an integrated control system would automate energy movement and exergy management within the system to provide energy capture and storage as well as distribution of stored energy to the HVAC system.

Modular prefabricated panels, containing the conduits for fluid transport that could be installed directly onto interior or exterior walls combined with the above, could then make the combined system affordable as a retrofit available to a majority of homeowners.

Even though this paper dealt with technology, we take the opportunity to highlight the need to reduce the climate impact of buildings. It is obvious that the most likely way this can be done is by converting hundreds of thousands of buildings, now climate controlled using fossil fuels into NZEBs. We now propose that for the first time, we have the tools to accomplish this.

In most locations, the cumulative number of annual sun shine hours that act on a typical detached dwelling's rooftop provides far more energy than the average annual household energy consumption [1]. GEST is designed to make use of this renewable resource to replace fossil fuels for climate control. EQM was 
designed to maximize the efficiency climate controlled by managing on site renewable energy resources that, for the first time, makes the implementation of GEST practical

Finally, we introduce a two-stage construction pattern that is equally applicable to new construction or retrofitting. This makes the system affordable. The second stage of a construction project, being based on the existing capital and design produced in stage one, gives the basis for obtaining a low-risk loan. By moving the second stage of construction to long-term low risk capital-based financing, millions of dollars will be generated for local contractors and suppliers i.e., provide a boost to the job market. Individual people will be able to improve comfort and reduce the cost of home ownership and as a society, carbon emissions will be reduced; this is a win-win-win solution.

Conflict of Interest: The authors declare no conflict of interest.

\section{References}

1. L. Lingo, Extending the Passive House Approach with Geo-solar Exergy Storage Technology; A Vision for reducing Purchased Energy Use in Existing and New Constructions, PhD Dissertation, Syracuse University, Syracuse, NY, (2011)

2. M. Bomberg, A. Romanska-Zapala, D. Yarbrough Energies. 2020; 13(5):1027 (2020).

3. M. Bomberg, D. Onysko, White paper, Energy efficiency and durability of buildings at the crossroads, Building Enclosure Technology and Environment Council, Nat. Bldg. Enclosure Council and Nat. Inst. of Building Science. BEST1 Conference (2008))

4. A. Romańska-Zapała, M. Bomberg, M. FedorczakCisak, M. Furtak, D. Yarbrough, M. Dechnik, J. Build. Phys., 41, 397-417 (2018)

5. D. Yarbrough, M. Bomberg, A. Romanska-Zapala, On the next generation of low energy buildings, Adv. In Building Energy Research, Special Publication 2019, DOI:10.1080/17512549.2019.1692070 (2019)

6. A. Romanska-Zapala, M. Bomberg, D. Yarbrough, J. Build. Phys., 43, 3-21(2018)

7. J. Hait, Passive Annual Heat Storage - Improving the Design of Earth Shelters, Rocky Mountain Research Center, Montana, Web (1983).

8. D. Stephens, Annualized Geo-Solar as a Sustainable Residential Scale Solution for Temperate Climates with Less Than Ideal Daily Heating Season Solar Availability, Available online:

http://api.ning.com/files/lIfSpEyhDKPw5QkbmpN SONIPCpG6aSi6zAnXSkujA2ptOsX88M113cY17sR24kf *STa5TyYxcylxySd0rO3fdyyvIAja92E/pahspaper. pdf (2005),

9. D. Booth, D. Clayton, B. Henninge, The Double shell Solar House, Community Builders, NH, 120 (1980)
10. A. Romanska-Zapala, M. Bomberg, M. Dechnik, M. Fedorczak-Cisak, and M. Furtak, Energies, 13 15, DOI: 10.3390/en13010015, (2019)

11. M. Bomberg, T. Brennan, H. Henderson, K. Stack, A. Wallburger, J. Zhang, High Environmental Performance (HEP) - residential housing for NY state. A Final Report to NY State Energy Research and Development Agency and Nat. Center of Energy Management and Building Technology, Manuscript, USA (2009)

12. T. Brennan, M. Bomberg, H. Henderson, K. Stack, Quality Assurance and Commissioning Process in High Environmental Performance (HEP) House in NY State. Available online: https://cdn.ymaws.com/www.nibs.org/resource/res mgr/BEST/BEST1_008.pdf (2008)

13. A. Wallburger, T. Brennan, M. Bomberg, H. Henderson, Energy prediction and monitoring in High Performance Syracuse house. http://thebestconference.org/BEST2_(2010)

14. M. Bomberg, A. Romanska-Zapala, D. Yarbrough, Reduction of the impact of residential buildings on climate change, prepared for J. Sustainability, special issue IEIE (2020)

15. C. Simonson, M. Salonvaara, T. Ojanen, J. Build. Phys, 28 (3) 161-185 (2004)

16. M. Bomberg, T. Kisilewicz, C. Mattock, Methods of building physics, Cracow Uni. Press, 1-301 (2017)

17. K. Klingenberg, M. Kernagis, M. Knezovich, J. Build. Phys, 39, 503-521 (2016)

18. G. Wright, K. Klingenberg, Climate-specific Passive Building Standards, U.S Department of Energy, Building America Program, Office of Energy Efficiency and Renewable Energy (2015)

19. Atelier Rosemount, Information news, Canadian Mortgage and Housing Corporation, (2016)

20. L. Lingo, U. Roy, J. Energy Eng., 143, 1, (2017). 